\title{
Exploration on the Application of Color Contrast and Harmony in Advertising Design
}

\author{
Yibing $\mathrm{Li}^{1}$ \\ ${ }^{1}$ Culture and Art Management, Honam University, South Korea \\ Correspondence: Yibing Li, Culture and Art Management, Honam University, South Korea.
}

Received: September 10, 2021

Accepted: September 29, $2021 \quad$ Online Published: September 30, 2021

doi:10.20849/ajsss.v6i3.934

URL: https://doi.org/10.20849/ajsss.v6i3.934

\begin{abstract}
This paper briefly summarizes the principle of color contrast and color harmony, which mainly explains their applications in advertising design. From the exploration, it is found that the moderate contrast, sharp contrast and progressive contrast of color are often employed in advertising design, furthermore, the identity harmony, approximate harmony and order harmony is also widely used in advertising design. Therefore, in order to better carry out the application of color contrast and harmony, the advertising design department should actively train professionals in color, strengthen advertising design review and conduct the all-around market research.
\end{abstract}

Keywords: color contrast, color harmony, advertising design

\section{Introduction}

With the comprehensive coverage of information network, more and more advertisements are filled with public life. As the market of advertising industry is in the state of prosperous development, and in the context of so many advertisements, consumers put forward higher requirements for advertising design. In order to strengthen the aesthetic feeling of advertisements and bring more comfortable advertising experience to consumers, paying attention to color contrast and harmony in advertising design has become the design trend.

\section{Overview of Color Contrast and Color Harmony}

In modern advertising design, most of the designers make more use of color contrast, since this way can better interpret the beauty of different colors, so as to make the whole advertising picture present a state of higher texture. This color form usually contrasts two and more colors at one time, thus fully reflecting the color differences within the limited space and further emphasizing the color. Color changes in the advertising design can show more intuitive feeling through contrast. Moreover, color changes can enrich the contents that will be expressed by the overall advertising picture, so that transferring three-dimensional effect and stimulating the nerves of consumers. In this way, such advertisements will leave a deep impression on consumers' minds, and they will perceive the advertising connotation in depth. The color contrast method that is commonly used is to take the warm colors as the advertising background, at the same time, using the cool colors to show the part of product display, so as to form the contrast of warm colors and cool colors of the whole advertising picture, and then highlight the product, which is the main body. Color harmony is often applied in advertising design, as the fusion of two or more colors in the advertising design can enrich the advertisement picture and make it rich in colors. During color harmony, it is important to pay more attention to the harmony of color combination and we must ensure the order of color, so as to convey comfortable visual sense to consumers. Color harmony can reconcile the colors with great differences in advertisements, on the other hand, it can help to avoid the effect of being too abrupt or lead to the visual oxymoron. Maintaining the overall color coordination of advertisements is the main purpose of color harmony.

\section{Application of Color Contrast in Advertising Design}

It is necessary to consider the theme of advertising when using color contrast. Different ways of color contrast are usually chosen in advertisements with different themes. For the commonly seen advertising themes nowadays, there are mainly three ways of color contrast that can be applied, which are moderate contrast, sharp contrast and progressive contrast. 


\subsection{Moderate Contrast}

In color contrast, the moderate contrast refers to the application of similar colors in advertising picture. At least two similar colors should be used in one same picture, and a variety of similar colors often appear in advertising design. The similar colors are softer, furthermore, the similar colors with similar hues and similar color levels are relatively mild in contrast. However, the similar colors with big gap in hues are quite different, which constitute a stronger sense of contrast. When using color contrast, similar colors with a small hue interval are often applied to form moderate contrast, so that achieving the softness of colors and realizing the effect of color contrast. Usually, pictures made up of similar colors are more beautiful and they can express the theme of advertisement in a better way. At present, many advertisements are likely to adopt moderate contrast when using different colors. Taking the advertisement of Crest in a year as an example, it firstly showed the dentists' working condition and the main color of picture is white. When adding the product into advertising, it used milky white teeth for highlighting. As milky white and white belong to similar colors, it makes the whole picture softer when forming color contrast, and with a sense of life, which is easy to shorten the psychological distance with consumers and improve the overall comfort of advertising. In this advertisement, there is no mix of bright colors, which makes the contrast between white and milky white more harmonious. Therefore, the content of whole advertisement is relatively fresh and will not appear to be disorganized. In addition to the Crest, many products advertisements of home life also apply the moderate contrast method to stress the main products, thus ensuring the beauty and harmony of advertising picture. At the same time, it can highlight the theme of advertising. Such advertisements with moderate contrast in color try to unify the tones in composition as far as possible, so as to present complete cool tones or warm tones, making the overall picture has a sense of life, what's more, the effect of advertising also will be better (Su, X-L., \& Zhang, J., 2020).

\subsection{Sharp Contrast}

In advertising design, the sharp contrast of color often can catch the attention of consumers. In general, products with obvious fashion feeling usually apply sharp contrast design techniques, such as fashion clothing, cool toys and so on. Due to the evident fashion feeling brought about by sharp contrast, most youth will be attracted by such advertising design. Under normal conditions, these advertising pictures apply more direct ways to present products, which can instantly grasp the attention of the public, thus leaving unforgettable impression on consumers through sharp contrast in color. In sharp contrast, black and red constitute better effect. Jumei.com had ever made this type of advertising design, which constructs visual contrast by using the sharp contrast of black and red. In this way, a strong visual impact will be felt by the audiences. On the other hand, combining with its advertising slogan "I speak for myself", the whole advertisement reflects the independent style of contemporary youth. It not only satisfies the eye-catching effect of the advertisement and improves the picture sense, but also highlights the theme of the advertisement, which make consumers easily associate with product characteristics, so the effect of publicity is excellent. In addition, an advertising poster of Nestle coffee also applied contrast of red and black. The advertisement constructed a situation that two lovers stared at one another face to face by using black silhouette. Meanwhile, a red coffee cup was set between the couple, with the caption "It all starts with a Nescafe". The sharp contrast make advertising picture full of artistic feeling as a whole, which bring aesthetic enjoyment to consumers through highlighting the product, so as to create the imaginative artistic conception and make the audiences get emotional resonance, thus deepening their impressions on this advertisement.

\subsection{Progressive Contrast}

In addition to the moderate contrast and sharp contrast, the progressive contrast also plays an important role in advertising design. This technique is more common in foreign countries, whose application in foreign advertising is more flexible than that in China. Generally speaking, the technique of progressive contrast mainly presents an effect of fantasy, which mostly brings the fantasy feeling to consumers. Let's take the advertisement of Disneyland as an example. It describes that a child couldn't sleep after saying good night with her parents, so she stared at the stars on the sky, then, the stars took her to Disneyland magically. Pushing open the gate of park, the camera shows various beautiful scenery and entertainment facilities in Disneyland. Such advertisement leads audiences to attractive scenery by adopting the special method, which makes both the plot expression and color expression being progressive by using progressive means. Therefore, it can be known that the progressive contrast of colors in advertising pictures can make the picture more eye-catching.

\section{Application of Color Harmony in Advertising Design}

Color contrast is mainly to deepen the advertising impression through visual impact, while the harmony of color pays more attention to users' visual enjoyment. Different colors can bring about different effects on consumers' 
psychological feeling, and then have an impact on their consumption demands. There are various methods of color harmony in advertising design, among which the identity harmony, approximate harmony and order harmony are the three most common ways. In the tone harmony, the area adjustment method, dominance method, enhancement method and intervention method can be selected for different harmony design in accordance with a variety of requirements in harmony.

\subsection{Forms of Harmony}

\subsubsection{Identity Harmony}

The identity harmony is mainly to reconcile colors with the same tone, among which the harmony in black, white and gray are used mostly. Moreover, all kinds of compound colors, secondary colors and primary colors also can use the method of identity harmony. Adopting the identity harmony in a limited advertising picture can make the overall picture color more harmonious. When using the identity harmony method, advertising designers often reconcile the pure tones to enlarge the sense of pictures, so that further highlighting the advertising theme (Yang, L-N., 2021).

\subsubsection{Approximate Harmony}

Approximate harmony refers to reconcile the pictures with similar colors in advertisements, which can make the pictures become softer through a variety of harmony means, so as to avoid consumers being unpleasant when seeing the mixed and disordered colors. Such harmony method is mainly used to cater to the preferences of consumers, which has proved to work a lot. Especially for advertisements designed in the emotional direction, using approximate harmony means to ease the picture perception can make advertisements contain more emotional function, and now the approximate harmony is the most widely used in many advertisements.

\subsubsection{Order Harmony}

Even though color is ever-changing, it also has a certain law in the process of change, so advertising design must focus on the order of color. The order of color depends on people's aesthetic appreciation of colors, among which the hue contrast order has the strongest basic of color structure. It can not only reflect the contrast effects of primary colors, showing the basic hue of the advertisement subject, but also make the advertisement produce a stable aesthetic feeling. Besides, there is the order contrast between warm color and cool color, which cannot be viewed separately in advertising, but need to set by combining the overall picture, and then to expand the influence of advertisements. The order of complementary color contrast is also used in most advertising design. As this order can form a strong effect, so human eyes need to maintain the visual balance through complementary color. Therefore, the advertising design with complementary color order can usually attract consumers more. The order of purity contrast should be given special attention in terms of order harmony, and the purity of color refers to the clarity and ambiguity of hue. In the advertising design, special attention is paid to the order of lightness, so as not to blur the theme of advertisements. Such color harmony means often appear in home decoration advertising, since the color order can ensure the harmony and beauty of the overall picture in limited space. Taking a latex paint advertisement as an example, it mainly highlights the different colors of different kinds of animals in advertising design. At the same time, the colors applied in this advertisement have certain orders, which shows the overall feeling of peaceful happiness in the zoo. Moreover, pictures of animals are dealt with order harmony, which not only ensures the richness of pictures, but also reflects the harmony of pictures (Cheng, M., 2020).

\subsection{Methods of Harmony}

\subsubsection{Area Adjustment Method}

This method is commonly seen in the advertising design whose base tone is complementary color or contrast color, which realizes the highlight of main tone through adjusting part of the color areas in the picture, and then further improves the overall picture sense of the advertisement.

\subsubsection{Color Dominance Method}

This method focuses on alleviating the problem of sharp contrast in picture. It dominants colors in some advertisements with too prominent color contrast, so as to moderate the existence of colors in the advertising picture. On the other hand, it coordinates the hue, lightness and purity to make the whole advertising picture more harmonious.

\subsubsection{Color Enhancement Method}

Using the color enhancement method in advertising design is more meaningful in practice, since it can change the color ring difference that appears in color hue. At the same time, it also can change the purity, adjust its 
lightness, thus making colors in advertising picture form the contrast effect and bring visual stimulation. Moreover, it can avoid the problem that advertisement picture is more boring because of colors are too monotonous.

\subsubsection{Color Intervention Method of Color}

When colors used in the advertising design are too colorful and bright, the picture can be mitigated by color intervention. Usually, designers add black, gray, white and other achromatic colors to the picture to reconcile the color conflict, thus bringing a more comfortable visual experience to the advertising audiences.

In addition, the color repetition method is also can be used, so as to realize the orderly interval or repetition by combining with the color order. In addition to changing the color itself, we can also change the arrangement of form elements in the advertising picture, such as pictures or words, so as to achieve the effect of color adjustment (Wang, Y-N., 2020).

\section{Ways to Strengthen the Application of Color Contrast and Harmony in Advertising Design}

\subsection{Cultivating Professionals in Color}

The use of color in advertising is obvious to all, so the work of color contrast and harmony needs to be given more attention. Therefore, it is necessary to train more professionals of advertising design. The modern society level never stopped the pace of development, with advertising development has entered a new era, advertising designer, as an important figure in the advertising industry, must closely follow the pace of the development of times, so as to constantly strengthen their learning awareness in color on advertising design and improve the ability in applying color contrast and harmony. Only when deeply realizing the importance of color contrast and harmony for advertising design, can we give full play to the great role of color contrast and harmony in the field and effectively promote the rapid development of the advertising industry. The employing units should take the ability of applying color contrast and harmony as one of the assessment contents of advertising design business, thus urging designers to attach great importance to self-improvement, and ensuring their quality in color. Designers not only need skilled design techniques, also need to improve their ability in color use. Color contrast and harmony presents their professional qualities, in order to strengthen the application in this field and improve the quality of advertising design, employing units should introduce more designers with higher professional quality and ability, also the designers who are especially sensitive to color using. At the same time, employing units should strengthen the training of existing designers and organize advertising design departments to learn colors regularly, so that making them improve their ability to use colors (Wang, X-X., Li, W-P., \& Wen, L-L., 2020).

\subsection{Strengthening the Advertising Design Review}

The final results of advertising design need to be reviewed for many times, in order to better use color contrast and harmony, the review procedures need to be strengthened. Adjusting all kinds of color problems in advertising design in time is more convenient for designers to reconcile the color problems, and ensure that the final design results meet the needs of market as well as the aesthetic of public. The weakening or lack of review is likely to lead to the unsatisfactory effect of advertisement, thus causing the color problems cannot be found and adjusted in time. At the same time, the review not only needs to examine the advertising creativity, color use and other issues from the perspective of advertising, but also needs to consider the color use of advertising from the perspective of the ordinary audiences. Especially for the products with a wide scale of audiences, only those advertisements that can bring people pleasant aesthetic feeling can get the favor of consumers. Consequently, advertising review needs to understand the colors in advertisements from the perspective of ordinary people, thus providing real feedback in color for advertising designers, which can help them to find the main direction of color contrast and harmony and realize the improvement of advertising quality.

\subsection{Conducting Market Research Actively}

The color contrast and harmony of advertising is inseparable from market research. First of all, it is necessary to investigate the popular colors of that year before designing an advertisement. For instance, in the clothing industry, the popular colors in 2021 are bright yellow, extreme gray, marigold orange, French blue, etc., which have very distinctive color characteristics. Bright yellow is full of vitality, extreme gray symbolizes the reason and French blue represents the elegance. After understanding the popular colors in season, designers can conduct advertising design according to characteristics of products by choosing appropriate colors for contrast and harmony. Advertising colors chosen under the basis of a series of survey are more acceptable to audiences. In addition to conduct survey on the popular colors, the market research on advertising colors targeting at the public is also needed. By collecting the audiences' opinions on previous advertising colors is conductive to color 
contrast and harmony in the new design scheme, so that ensuring the design results conform to the aesthetic needs of the masses and avoiding useless work behind closed doors. Even if the color contrast and harmony is made, the advertising contents still also cannot get the public love and recognition without market research as the support, so market research is an essential and important step in advertising design.

\section{Conclusion}

In a word, advertising design requirements more in color, especially in the face of the public, it needs more preference from them. Accordingly, the designers needs to fully consider the color contrast and harmony in the process of designing. By cultivating professionals in color, strengthening advertising design review and conducting market research actively, the application of color contrast and harmony in advertising design can be greatly improved.

\section{References}

Cheng, M. (2020). The Beauty of "Contrast" and "Harmony" in the Traditional Colors of Beijing. Popular Color, (8), 34-39.

Su, X-L., \& Zhang, J. (2020). Application of Color Contrast and Harmony in Advertising Design. Artists, (4), 123-124.

Wang, X-X., Li, W-P., \& Wen, L-L. (2020). Application of Colors in New Media Print Advertising Design. Computer Knowledge and Technology, 16(18), 188-189.

Wang, Y-N. (2020). Color Contrast and Harmony in Decorative Painting. Peony, (12), 79-80.

Yang, L-N. (2021). Expression of Color Composition Principle in Poster Design. Western Leather, 43(8), 40-41.

\section{Copyrights}

Copyright for this article is retained by the author(s), with first publication rights granted to the journal.

This is an open-access article distributed under the terms and conditions of the Creative Commons Attribution license (http://creativecommons.org/licenses/by/4.0/). 